\title{
Chemical composition and potentiating action of Norfloxacin mediated by the essential oil of Piper caldense C.D.C. against Staphylococcus aureus strains overexpressing efflux pump genes
}

\author{
Antonio Linkoln Alves Borges Leal ${ }^{1,2} \cdot$ Camila Fonseca Bezerra $^{3} \cdot$ Camila Confortin $^{10} \cdot$ Luiz Everson da Silva $^{10}$. \\ Emanuelle Machado Marinho $0^{5}$. Márcia Machado Marinho ${ }^{6}$. Mayron Alves Vasconcelos ${ }^{7}$. \\ Terezinha Gonçalves da Silva ${ }^{8}$. Emmanuel Silva Marinho ${ }^{9}$. Alexandre Magno Rodrigues Teixeira ${ }^{1}$. \\ Henrique Douglas Melo Coutinho ${ }^{1} \cdot$ Humberto Medeiros Barreto ${ }^{2} \cdot$ Hélcio Silva dos Santos $^{1,4}($ )
}

Received: 7 November 2020 / Revised: 14 May 2021 / Accepted: 20 May 2021 / Published online: 29 May 2021

(c) The Author(s), under exclusive licence to Springer-Verlag GmbH Germany, part of Springer Nature 2021

\begin{abstract}
Infectious diseases caused by multidrug-resistant microorganisms has increased in the last years. Piper species have been reported as a natural source of phytochemicals that can help in combating fungal and bacterial infections. This study had as objectives characterize the chemical composition of the essential oil from Piper caldense (EOPC), evaluate its potential antimicrobial activity, and investigate the synergistic effect with Norfloxacin against multidrug-resistant $S$. aureus overproducing efflux pumps, as well as, verify the EOPC ability to inhibit the Candida albicans filamentation. EOPC was extracted by hydrodistillation, and the chemical constituents were identified by gas chromatography, allowing the identification of 24 compounds (91.9\%) classified as hydrocarbon sesquiterpenes (49.6\%) and oxygenated sesquiterpenes (39.5\%). Antimicrobial tests were performed using a 96-well plate microdilution method against $C$. albicans ATCC 10231, Escherichia coli ATCC 25922 and Staphylococcus aureus ATCC 25923 standard strains, as well as against multidrug-resistant strains $S$. aureus SA1199B (overexpressing norA gene), S. aureus K2068 (overexpressing mepA gene) and S. aureus K4100 (overexpressing qacC gene). The oil showed activity against $C$. albicans ATCC $10231(\geq 512 \mu \mathrm{g} / \mathrm{mL})$ and was able to inhibit hyphae formation, an important mechanism of virulence of $C$. albicans. On the other hand, EOPC was inactive against all bacterial strains tested $(\leq 1,024 \mu \mathrm{g} \mathrm{mL})$. However, when combined with Norfloxacin at subinhibitory concentration EOPC reduced the Norfloxacin and Ethidium bromide MIC values against S. aureus strains SA1199B, K2068 and K4100. These results indicate that EOPC is a source of phytochemicals acting as NorA, MepA and QacC inhibitors.
\end{abstract}

Keywords Essential oil $\cdot$ Piper caldense $\cdot$ Antibacterial $\cdot$ Efflux pump inhibitors $\cdot$ Antifungal $\cdot$ Fungal dimorphism

Communicated by Erko Stackebrandt.

Hélcio Silva dos Santos

helciodossantos@gmail.com

1 Department of Biological Chemistry, Regional University of Cariri, Crato, CE, Brazil

2 Department of Microbiology and Parasitolog, Federal University of Piaui, Teresina, PI, Brazil

3 Department of Pharmaceutical Sciences, Federal University of Pernambuco, Recife, PE, Brazil

4 Center for Exact Sciences and Technology, Vale do Acarau State University, Sobral, CE, Brazil

5 Department of Analytical Chemistry and Physical Chemistry, Federal University of Ceará, Fortaleza, CE, Brazil
6 Faculty of Education, Science and Letters of Iguatu, State University of Ceará, Iguatu, CE, Brazil

7 Minas Gerais State University, Divinópolis Unit, MG, Brazil

8 Department of Antibiotics, Drug Planning and Synthesis Laboratory-LPSF, Federal University of Pernambuco, Cidade Universitária, Recife, PE, Brazil

9 Group of Theoretical Chemistry and Electrochemistry, State University of Ceará, Campus FAFIDAM, Limoeiro do Norte, Fortaleza, CE, Brazil

10 Postgraduate Programme in Sustainable Territorial, Federal University of Paraná, Curitiba, PR, Brazil 


\section{Introduction}

Infectious diseases caused by multidrug-resistant microorganisms has become a global public health concern (Guschin et al. 2015). Multidrug-resistant bacteria have been isolated with high frequencies from community or hospital-acquired infections (Klein et al. 2020; Xiang et al. 2020), as well as, from infections of veterinary importance (Lima et al. 2012). On the other hand, infections caused by resistant fungi are more and more prevalent in hospitals, being known as a sleeping giant, for never having completely solved the problem of ineffective antifungals (Veríssimo et al. 2016). In fact, antimicrobial resistance it was predicted to reach pandemic proportions by 2050 , accounting for 10 million deaths annually (Sugden et al. 2016).

Antibiotic resistance can acquired by a mutation that generate a change in a target protein with lower for affinity for antibiotic or through acquisition of resistance placed in plasmids, transposons or phage DNA that often involves inactivation, antibiotic degradation or extrusion by active efflux pumps (Santos et al. 2007). Efflux pumps are transmembrane proteins that become both bacteria and fungi resistant, because they are able to extrude antibiotics and biocide reducing their intracellular concentrations using ATP or proton gradient as energy source (Du et al. 2018).

Traditionally used antibiotics have been losing their effectiveness because of increased microbial resistance (Mayers et al. 2009). Epidemiological studies warn of the importance of further research for discovery of new drugs or compounds with therapeutic properties (Balouiri et al. 2016). Another important point, to combat infections caused by resistant microorganisms, is the discover of compound acting as efflux pump inhibitors to provide new ways to reverse bacterial and fungal resistance (Rezende-Júnior et al. 2020). In this way, alternative forms such as in vitro methods in antimicrobial tests to assess the potential of extracts, essential oils, and isolated compounds have been intensified, revealing potential antimicrobial agents or even enhancing the activity of antibiotics used in clinical practice (Balouiri et al. 2016; Coutinho et al. 2008, 2010; Matias et al. 2013; Costa et al. 2017; Siebra et al. 2018). The association of natural products as well as the use of these combined with antimicrobials, has been widely discussed in the scientific literature, given the ability to provide antimicrobial efficacy in previously ineffective doses due to the antimicrobial resistance presented by some strains (Guimaraes et al. 2010; Silva et al. 2014; Tulgar et al. 2018).

The inhibition of the production of virulence factors by pathogenic microorganisms is also an approach that can be useful in the treatment of infectious diseases. Candida species, produce infections ranging from skin and mucous infections, to deep and generalized infections, they make use of alternative mechanisms to invade the host organism and develop virulence factors, where they colonize significantly, leaving the responses to aggression, weakened (Egue et al. 2018). C. albicans is the species responsible for about $50-70 \%$ of the cases of invasive candidiasis (Castro et al. 2016). C. albicans is a yeast species capable of producing hyphae or pseudo-hyphae able to invade host tissues leading to candidiasis (Fernandes et al. 2020; Sellam and Whiteway 2016). The ability to alter structural morphology from yeast to filamentous cells, is known as one of the main mechanisms of fungal virulence (Hou et al. 2011; Sánchez-Martínez and Pérez-Martín 2001).

Natural products with antimicrobial properties represent an alternative to the use of traditional antimicrobial agents. Piper caldense C.D.C. (Piperaceae) is a shrub popularly known as "pimenta d'agua" that has been used in some Brazilian regions as a sedative agent (Cardozo Júnior and Chaves 2003). This study aimed to characterize the chemical composition of the essential oil from the leaves of Piper caldense (EOPC), as well as, its antimicrobial activity against bacteria and yeast strains. The ability of the EOPC to inhibit cell dimorphism in C. albicans was also assessed. Futhermore, the effect of the EOPC on the activity of Norfloxacin against multidrug-resistant $S$. aureus SA1199B, S. aureus K2068 and S. aureus K4100 strains was assessed to evaluate its potential as inhibitor of the NorA, MepA or QacC efflux pumps.

\section{Materials and methods}

\section{Botanical material}

Plant material was collected in the dense lowland rainforest, Antonina, PR 2015/2106, Brazil, under coordinates $25^{\circ} 17^{\prime} 51.9^{\prime \prime} \mathrm{S}$ and $48^{\circ} 40^{\prime} 51.4^{\prime \prime} \mathrm{W}$ at $14 \mathrm{~m}$ elevation, during the spring. Material collection was carried out under license from the Environmental Institute of the Paraná State, number 284/11, and an exsiccata was deposited at the Herbarium of the Municipal Botanical Museum (MBM) in Curitiba, PR, under No. 267636. Fresh leaves of $P$. caldense were used to extract the oil without any indication of contamination by parasites.

\section{Extraction of the essential oil}

The oil was prepared by hydrodistillation using a Clevenger graduated device. The proportion of fresh leaves was $100 \mathrm{~g} / \mathrm{L}$ of distilled water, following the methodology described by Wasicky (1963). An electric dryer modelFANEM $320 \mathrm{SE}$ was used, with air circulation at $40^{\circ} \mathrm{C}$ for 
$24 \mathrm{~h}$ to dry the leaves. Following to determine the moisture content at the time of extraction, samples of $20 \mathrm{~g}$ were collected in triplicates, submitted to drying in an electric dryer model FANEM $320 \mathrm{SE}$ with air circulation at $65^{\circ} \mathrm{C}$ until reaching constant weight. After extraction, the samples were collected with a precision pipette and placed in a freezer where they remained until the time of the chromatographic analysis.

\section{Strains and chemicals}

Evaluation of the intrinsic antimicrobial activity of the EOPC was performed against standard microbial strains Staphylococcus aureus ATCC 25923, Escherichia coli ATCC 25922 and Candida albicans ATCC 10231, as well as, against multidrug-resistant strains $S$. aureus SA1199B overexpressing the norA gene (Kaatz et al. 1993), S. aureus K2068 overexpressing the mepA gene (Kaatz et al. 2005) and S. aureus K4100 overexpressing the qacC gene (Littlejohn et al. 1991). Assays for evaluation of the modulating effect on drug resistance were performed only with drug-resistant S. aureus SA1199B, K2068 and K4100 strains. Assays for evaluation of the ability to inhibit the cellular dimorphism were conducted against $C$. albicans ATCC 10231 strain. Bacterial and yeast strains were maintained on Brain Heart Infusion Agar (BHIA, Himedia, India) slants at $4{ }^{\circ} \mathrm{C}$, and prior to assay the cells were grown overnight at $37{ }^{\circ} \mathrm{C}$ in Brain Heart Infusion (BHI, Himedia, India). Subsequently, an aliquot of each microbial culture was removed and diluted in $3 \mathrm{~mL}$ of $0.9 \%$ saline, and the turbidity adjusted to the McFarland 0.5 scale.

Norfloxacin (Nor), Ethidium Bromide (EtBr) and Chlorpromazine (CPZ) were obtained from Sigma Chemical Corp., St. Louis. With the exception of Nor that was dissolved in a mixture of $1 \mathrm{M} \mathrm{NaOH}$ and sterile distilled water (1:9 proportion), EtBr and CPZ were dissolved in sterile water.

\section{Determination of the minimum inhibitory concentration (MIC).}

Initially, the essential oil was diluted in dimethylsulfoxide (DMSO) at a concentration of $10,000 \mu \mathrm{g} / \mathrm{mL}$. Subsequently, this solution was diluted in sterile distilled water to a concentration of $1024 \mu \mathrm{g} / \mathrm{mL}$. The minimum inhibitory concentration of EOPC against bacteria and fungi strains was determined using the 96-well plate microdilution technique. Initially, $100 \mu \mathrm{L}$ of essential oil was diluted serially in BHI $10 \%$ medium in concentrations that ranged from 1024 to $8 \mu \mathrm{g} / \mathrm{mL}$. Subsequently, $100 \mu \mathrm{L}$ of the microbial suspension (bacteria or fungi) in BHI $10 \%$ was added. For the control of microbial growth, BHI $10 \%$ was composed and microbial suspension in the absence of essential oil (Leal et al. 2019a) The plates were incubated at $37^{\circ} \mathrm{C}$ for $24 \mathrm{~h}$, and the MIC was identified by adding $20 \mu \mathrm{L}$ of sodium resazurin to each well and after $1 \mathrm{~h}$ visually checking the presence or absence of colorimetric change.

Fungal viability was achieved by adding a sterilized stem to each well that did not show fungal growth and subculturing in an Sabouraud Dextrose Agar (SDA, Himedia, India) petri dish. The plates were incubated at $37^{\circ} \mathrm{C}$ for $24 \mathrm{~h}$ and, subsequently, the development or suppression of fungal colonies (Morais-Braga et al. 2016) was verified.

\section{Modulating effect of the antibiotic resistance}

To evaluate if the EOPC was able to modulate antibiotic resistance in $S$. aureus strains overexpressing specific efflux pump genes, antibiotic MICs were determined in the presence or absence of subinhibitory concentrations of EOPC (1/8 or 1/4 MICs). Antibiotic concentrations ranged from 0.125 to $128 \mu \mathrm{g} / \mathrm{mL}$. The microtiter plates were incubated at $37{ }^{\circ} \mathrm{C}$ for $24 \mathrm{~h}$ and readings were performed with resazurin as described above. To verify whether the modulation of drug resistance occurred due to inhibition of the efflux pump, the modulation assay was performed by substituting antibiotics for EtBr, which is a known substrate of efflux pumps (Markham et al. 1999), used herein as inhibition of the pump. Control trials were also performed, replacing each natural product with $\mathrm{CPZ}$, which is a known efflux pump inhibitor (Neyfakh et al. 1993).

\section{Effect of $P$. caldense essential oil on $C$. albicans micromorphology}

The tests were performed according to Sidrim and Rocha (2010), with some modifications. In this test, the effect of the EOPC on the suppression of the filament of C. albicans was verified. Depleted Potato Dextrose Agar (PDA) was placed inside of Falcon tubes and, then the EOPC was added varying the concentration according to MIC as follow: MIC $(512 \mu \mathrm{g} / \mathrm{mL}), \mathrm{MIC} 1 / 2(256 \mu \mathrm{g} / \mathrm{mL})$ and MIC 1/4 (128 $\mu \mathrm{g} /$ $\mathrm{mL})$. Then, PDA was immediately poured in a slide. Petri dishes with a blade were inoculated by a calibrated loop $(1 \mu \mathrm{g})$, where two parallel streaks were made in the medium already solidified and then covered by a sterile microscopic sheet. After incubation at $24 \mathrm{~h}\left(37^{\circ} \mathrm{C}\right)$, the culture was visualized by optical microscopy. A control without the EOPC was made for the growth of yeasts whose hyphae emission was stimulated by the impoverishment of the medium, once stress caused by starvation leads to hyphae emission. 


\section{Statistical analysis}

Data were analyzed using the statistical program GraphPad Prisma 6.0. Differences between treatment with Norfloxacin and treatment with Norfloxacin combined with EOPC (or Chlorpromazine) were analyzed using a two-way ANOVA test, using the geometric mean of the triplicates as the central data and standard deviation. Then, a post hoc

Table 1 Relative percentage of essential oil components from fresh samples of native species of Piper caldense collected in the lowland rainforest, Antonina, $\mathrm{PR}-$ Brazil

\begin{tabular}{lrrr}
\hline Compounds & $\mathrm{IR}^{\mathrm{a}}$ & $\mathrm{IR}^{\mathrm{b}}$ & $\%$ \\
\hline$\alpha$-Pinene & 939 & 932 & 0.8 \\
Camphene & 952 & 946 & 2.1 \\
$\alpha$-Copaene & 1375 & 1374 & 2.8 \\
trans-Caryophyllene & 1417 & 1417 & 2.6 \\
$\beta$-Copaene & 1427 & 1430 & 0.9 \\
Trans- $\alpha$-bergamotene & 1435 & 1432 & 2.7 \\
$\gamma$-Muurolene & 1475 & 1478 & 6.0 \\
$\alpha$-Amorfene & 1479 & 1483 & 3.3 \\
$\beta$-Selinene & 1483 & 1489 & 3.2 \\
Valencene & 1492 & 1496 & 6.7 \\
$\alpha$ Muurolene & 1498 & 1500 & 4.2 \\
$\delta$-Cadinene & 1512 & 1522 & 13.9 \\
Humulene epoxide II & 1605 & 1608 & 1.0 \\
$\alpha$-Calacorene & 1541 & 1544 & 1.2 \\
$\beta$-Calacorene & 1564 & 1564 & 1.9 \\
Spathulenol & 1575 & 1577 & 9.1 \\
Caryophyllene oxide & 1579 & 1582 & 11.9 \\
Rosifoliol & 1597 & 1600 & 1.3 \\
1,10 di-epi-Cubebol & 1611 & 1618 & 1.6 \\
1-epi-Cubenol & 1625 & 1627 & 3.4 \\
epi- $\alpha$-Muurolol & 1639 & 1640 & 3.1 \\
$\alpha$-Muurolol & 1644 & 1644 & 1.8 \\
$\alpha$-Cadinol & 1652 & 1652 & 4.2 \\
Cadalene & 1672 & 1675 & 2.3 \\
Total identified $\%)$ & & & 91.9 \\
\hline & & & \\
\hline
\end{tabular}

${ }^{\mathrm{a}} \mathrm{I} . \mathrm{R}=$ Calculated Retention Index

${ }^{b} \mathrm{I} . \mathrm{R}=$ Literature Retention Index
Bonferroni test was performed and $p$ values $<0.05$ were considered significant.

\section{Results and discussion}

\section{Chemical composition}

The content of the EOPC was $14.74 \%$ and 24 constituents (91.9\%) were identified (Table 1). Chemical compounds were separated into groups, according to their chemical classification as hydrocarbon sesquiterpenes (49.6\%), oxygenated sesquiterpenes (39.5\%) and hydrocarbon monoterpenes $(2.9 \%)$. Oxygenated monoterpenes were not found in the EOPC. Caryophyllene oxide (11.9\%) was the major constituent found, followed by $\delta$-Cadinene $(9.6 \%)$ and Spathulenol (9.1\%) (Fig. 1). Chemical composition of the EOPC used in the present study (from Antonina, PR at 14 m elevation) was different to that verified by the EOPC from Piraquara, PR (528 m elevation), with nine different compounds as follow: trans-Caryophyllene, $\beta$-Copaene, Trans- $\alpha$-bergamotene, $\alpha$-Amorfene, $\beta$-Selinene and Valencene (Bezerra et al. 2020). Variations in the chemical composition of the EOPC are probably associated with different edaphomatic and rainfall conditions in the region where the specimen was found (Viana et al. 2019). Seasonality, circadian rhythm, temperature and brightness, as well as the stage of development and nutritional factors, are all likely to influence the chemical composition of essential oils.

\section{Evaluation of the antimicrobial activity}

MIC values above $1000 \mu \mathrm{g} / \mathrm{mL}$ for plant extracts have been considered as clinically irrelevant, because it may be impracticable to extrapolate the dose from that giving activity in vitro, to that which would be required in equivalence for the size of a human adult (Houghton et al. 2007). Using this value as a cutoff point, the EOPC did not show antimicrobial activity against bacterial strains tested (Table 2). Similar results were verified for other Piper species, such as, $P$. rivinoides (Leal et al. 2019b) and Piper cernuum (Leal et al. 2019a) that also did not present activity against both
Fig.1 Majority constituents of essential oil of Piper caldense

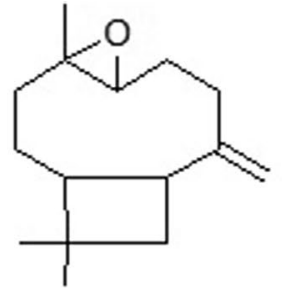

Caryophyllene oxide<smiles>CC1=CC2C(=C(C)CCC2C(C)C)CC1</smiles>

8-Cadinene<smiles></smiles>

Spathulenol 
Table 2 Minimum Inhibitory Concentration (MIC) values obtained for $P$. caldense essential oil (EOPC) against microbial strains tested

\begin{tabular}{lll}
\hline Strains & MIC $(\mu \mathrm{g} / \mathrm{mL})$ & Effect \\
\hline Staphylococcus aureus SA1199B & $\geq 1024$ & Inactive $^{\mathrm{a}}$ \\
Staphylococcus aureus K2068 & $\geq 1024$ & Inactive \\
Staphylococcus aureus K4100 & $\geq 1024$ & Inactive \\
Staphylococcus aureus ATCC 25923 & $\geq 1024$ & Inactive \\
Escherichia coli ATCC 25922 & $\geq 1024$ & Inactive \\
Candida albicans ATCC 10231 & 512 & Active \\
\hline
\end{tabular}

${ }^{\mathrm{a}} \mathrm{MIC}$ values upper than $1000 \mu \mathrm{g} / \mathrm{mL}$ were considered inactives (Houghton et al. 2007)

S. aureus and E. coli. However, a previous studies found a diferente result where the EOPC showed activity against Gram-negative Klebsiella pneumoniae, and Pseudomonas aeruginosa, as well as, against Gram-positive species $S$. aureus and Bacillus subtilis (Rocha et al. 2016).

EOPC tested in the present showed a weak antifungal activity against $C$. albicans ATCC 10231 (Table 2). This antifungal activity could be related with the presence of some constituents such as Caryophyllene oxide, a compound described as showing antifungal activity against $C$. albicans and dermatophyte fungi (Ghavam et al. 2020; Schmidt et al. 2010; Yang et al. 1999). However, the Caryophyllene oxide content found in the oil tested in the present study was lower (11.9\%) than that verified for the EOPC from Piraquara, PR (13.9\%), which did not show activity against $C$. albicans INCQ40006 and $C$. albicans URM4387 (Bezerra et al. 2020). Thus, we cannot rule out that other oil constituents acting isolatelly or synergistically could be related with the antifungal activity showed by the EOPC tested in the present study. As an example, Spathulenol, a sesquiterpene reported to be between major volatile components of the essential oils of several aromatic Piperaceae species, has some biological activities, including antimicrobial activity (Dib et al. 2017). Coming from the cyclization of nerolidine pyrophosphate, $\delta$-cadinene presents a cadinane skeleton, which the precursor is the farnesyl pyrophosphate (RuizReyes and Suarez 2015). Among the activities reported in the literature for $\delta$-cadinene can be mentioned the antitumor activity (Wright and Sutherland 2007), antimicrobial activity (Skaltsa et al. 2003). Thus, the antifungal activity observed in our approach could be associated to the levels of the compounds related to the local environments and conditions to which the assayed plant was exposed, acting possibly by a synergistic effect.

However studies with essential oils with species of Piper cernuum and $P$. caldense made by Duarte et al. (Duarte et al. 2016) and Constantin et al. (Costantin et al. 2001) present compounds that present several properties, among them antifungal, antibacterial and even capable of potentiating antibiotic effect. However, Costantin et al. (2001) who used the essential oil of P. cernnum and the compound Eugenol, demonstrated antifungal activity on $C$. albicans. The oil presented an inhibition halo of $12.2 \pm 0.6 \mathrm{~mm}$ in diameter, and the Eugenol isolate $28.9 \pm 1.3 \mathrm{~mm}$.

\section{Evaluation of the modulating effect of the antibiotic resistance}

EOPC potentiated the activity of Norfloxacin against $S$. aureus SA1199B overproducing NorA, as well as, against S. aureus K2068 overproducing MepA at subinhibitory concentrations. MIC values for Norfloxacin against SA1199B decreased eightfold in the presence of the oil from 64 to $8 \mu \mathrm{g} / \mathrm{mL}$ (Fig. 2A). For K2068 strain, MIC values for Norfloxacin also were reduced eightfold when the EOPC was added to the growth medium from 16 to $2 \mu \mathrm{g} / \mathrm{mL}$ (Fig. 3A). These results indicate that EOPC contains phytochemicals able to modulate the Norfloxacin resistance, probably by inhibition of the NorA and MepA efflux pumps.
Fig. 2 MIC values of Norfloxacin (Nor) (A) and Ethidium Bromide (EtBr) (B) against S. aureus SA1199B (norA) in absence or presence of the essential oil from the leaves of $P$. caldense (EOPC) or Chlorpromazine (CPZ). Each result represents the geometric mean of three simultaneous experiments. (***) Statistically significant values $(p<0.0001)$
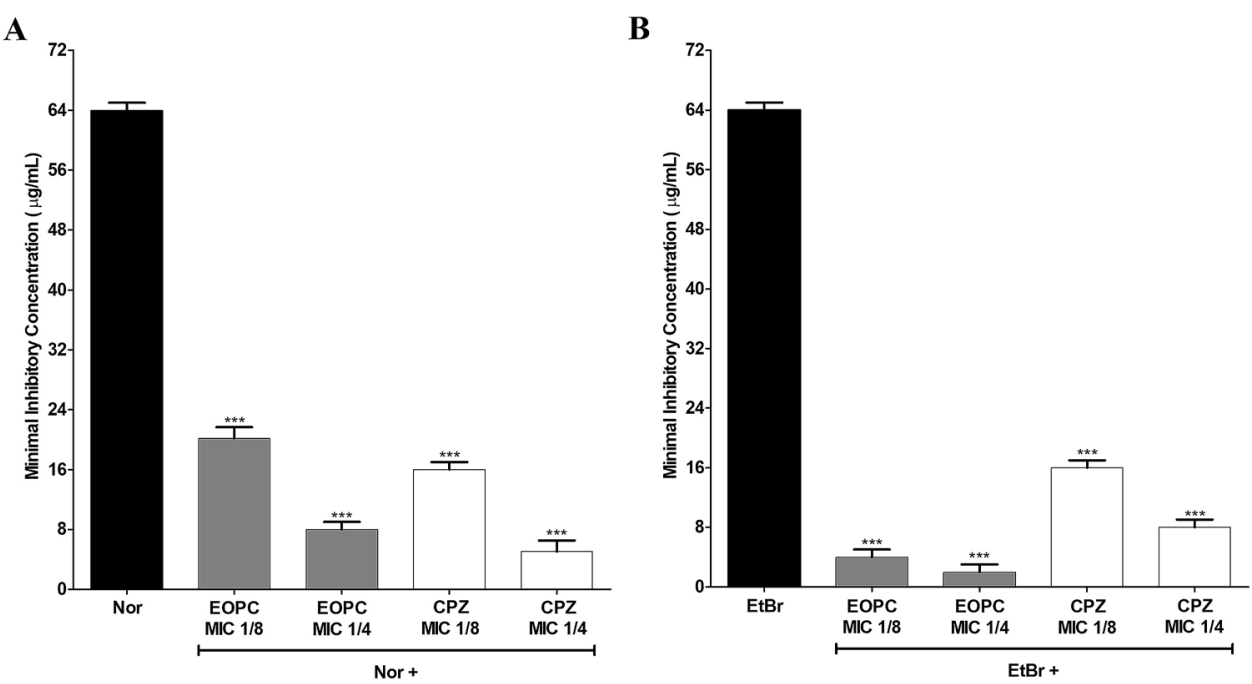
Fig. 3 MIC values of Norfloxacin (Nor) (A) and Ethidium Bromide (EtBr) (B) against S. aureus $\mathrm{K} 2068$ (mepA) in absence or presence of the essential oil from the leaves of $P$. caldense (EOPC) or Chlorpromazine (CPZ). Each result represents the geometric mean of three simultaneous experiments. (***) Statistically significant values $(p<0.0001)$
A

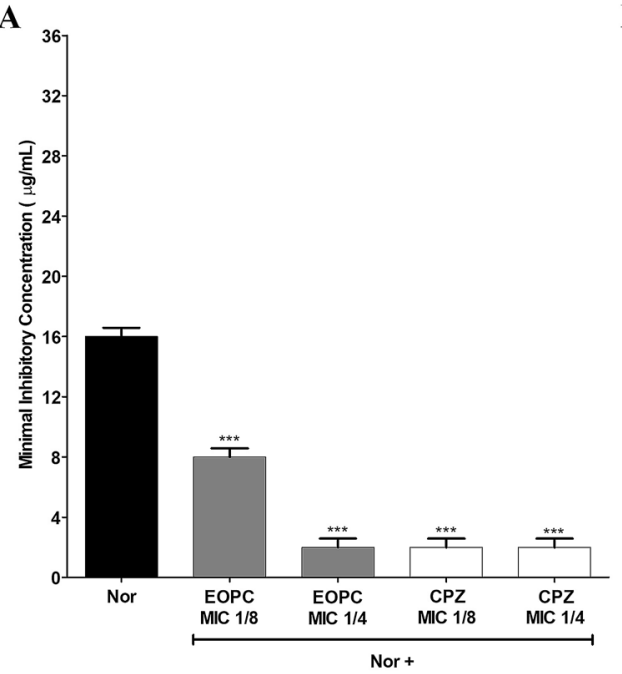

B

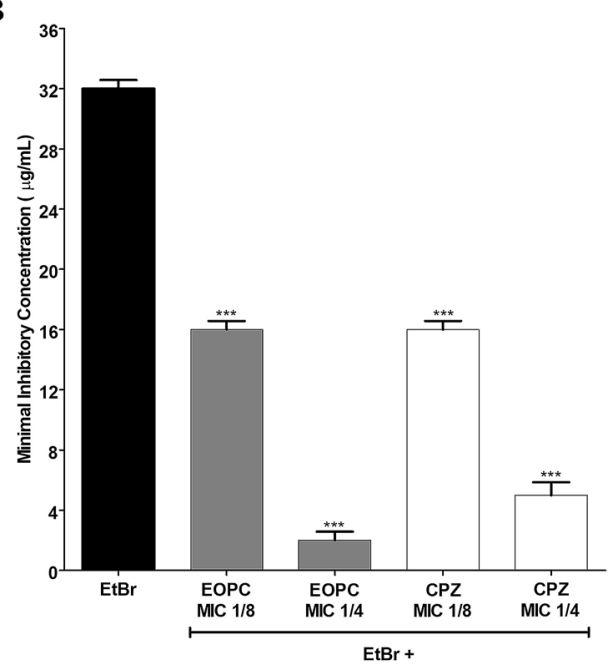

To verify if the modulating effect is related with efflux pump inhibition, assays were performed replacing Norfloxacin by EtBr. As the only known mechanism of bacterial resistance to $\mathrm{EtBr}$ is mediated by efflux pumps (Markham et al. 1999), this DNA-intercalating dye have been used to evaluate the potential efflux pump inhibitory activity of natural products (Silva et al. 2021a), isolated phytochemicals (Silva et al. 2021b) and synthetic compounds (Faillace et al. 2021; Costa et al. 2016). Results showed that EOPC was also able to modulate the resistance to EtBr in both SA1199B (Fig. 2B) and K2068 (Fig. 3B) strains. These results indicate the presence of compounds acting as NorA and MepA inhibitors which could be used against Norfloxacin-resistant S. aureus strains overproducers of efflux pumps, leading to a higher antibiotic accumulation in the bacterial cell.

NorA is a proton motive-dependent efflux pump belongs to Major Facilitator Superfamily (MFS), meanwhile MepA is a member of the Multidrug and Toxin Extrusion (MATE) superfamily, which is dependent of $\mathrm{H}^{+}$or $\mathrm{Na}^{+}$gradient to extrude Norfloxacin or EtBr (Schindler et al. 2014). To guarantee the integrity and functioning of NorA, there must be a continuous proton-driving force, integrity of DNA zones responsible for the synthesis of membrane proteins and balance in the permeability of substances inside the cell (Thai et al. 2015). The modulating effect verified for EOPC could be provoked by interaction of their hydrophobic monoterpenes and sesquiterpenes constituents, leading to plasma membrane damage and dissipation of the proton gradient (Souza et al. 2013; Ahmad et al. 2013), resulting in the NorA and MepA inhibition. As a consequence, the intracellular concentrations of Norfloxacin becomes enough to inactivate their intracellular targets increasing its antibacterial effect against the $S$. aureus strains tested. Thus, the EOPC could be used in combination to Norfloxacin aiming to enhancing the effectiveness of this antibiotic against multidrug-resistent S. aureus overproducers of NorA or MepA.
Similar results were found for $S$. aureus K4100 overexpressing the qacC gene (Littlejohn et al. 1991) once the EOPC potentiate the activity of $\mathrm{EtBr}$, indicating that the oil is able to inhibit QacC. MIC values for EtBr against K4100 decreased eightfold in the presence of the oil from 32 to $4 \mu \mathrm{g} /$ $\mathrm{mL}$ (Fig. 4). QacC is a proton motive-dependent efflux pump that confer resistance to EtBr and quaternary ammonium compounds (QACs), as Benzalkonium Chloride (Schindler et al. 2014). Biocide agents such as QACs are widely used

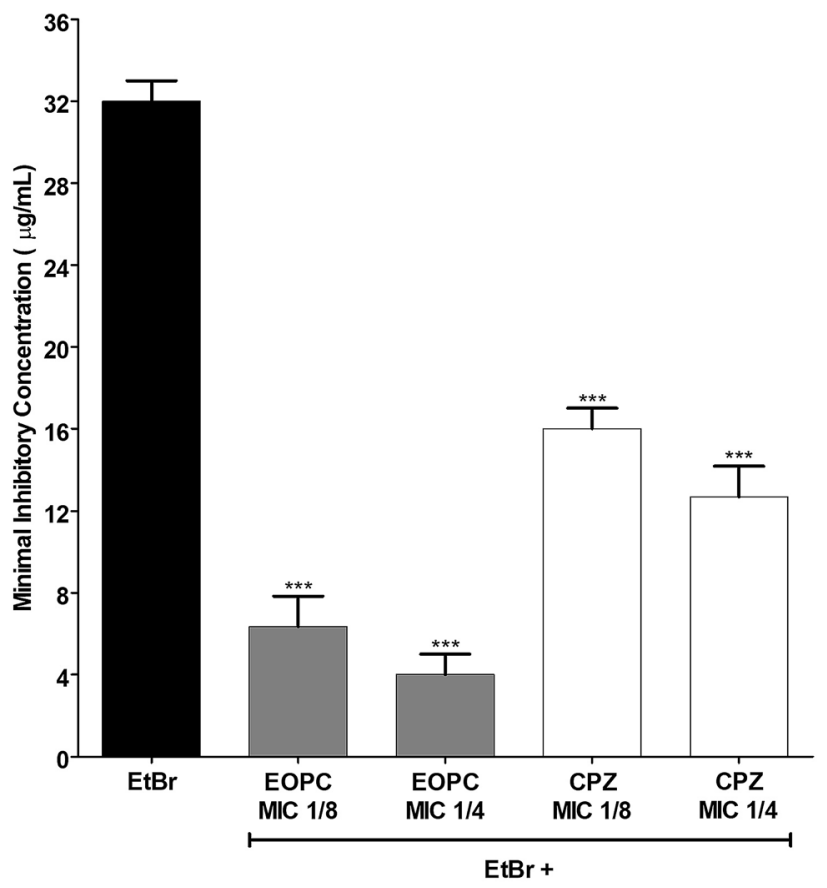

Fig. 4 MIC values of Ethidium Bromide (EtBr) against $S$. aureus $\mathrm{K} 4100$ ( $q a c C)$ in absence or presence of the essential oil from the leaves of $P$. caldense (EOPC) or Chlorpromazine (CPZ). Each result represents the geometric mean of three simultaneous experiments. $(* * *)$ Statistically significant values $(p<0.0001)$ 
in the disinfection of surfaces mainly in hospitals, outpatient clinics, dentist offices, as well as, veterinary clinics, being including effectiveness in the SARS-CoV inactivation (Kamp et al. 2020). This intensive use can contribute for emergence of QAC-resistant $S$. aureus strains overproducers of QacC (Schindler et al. 2014). Thus, the EOPC could be used in association with QACs aiming to eliminate these multidrug strains present in surfaces preventing outbreaks of $S$. aureus infections in hospital environments.

\section{Inhibition of the cellular dimorphism in C. albicans}

Assays for evaluation of morphological transition of $C$. albicans were performed in the presence and absence of subinhibitory concentrations of EOPC. The fungus grown in the absence of oil showed a clear morphological transition, being possible to observe the presence of blastospores and hyphae (Fig. 5). On the other hand, EOPC showed potential to inhibit fungal dimorphism at $512 \mu \mathrm{g} / \mathrm{mL}$ (MIC) and at subinhibitory concentration $256 \mu \mathrm{g} / \mathrm{mL}$ (MIC 1/2). However, at $128 \mu \mathrm{g} / \mathrm{mL}$, it was possible to observe the presence of pseudo-hyphae. Thus, besides antifungal activity, EOPC demonstrating a clear inhibition of the morphological transition in C. albicans ATCC 10231. Results found for EOPC tested in the present study were better than those found by Bezerra et al. (2020) once they verified inhibition of hyphae projection just at $2048 \mu \mathrm{g} / \mathrm{mL}$.

Hyphae projection by fungi such as $C$. albicans is an adaptation process to environmental changes such as temperature, $\mathrm{pH}$ or nutrient depletion, and filamentous forms generally promote invasive diseases and hinder the action of antifungals (Wightman et al. 2004; Barbedo and Sgarbi 2010; Veses and Gow 2014). Development of pseudo-hyphae by C. albicans increases its ability to adhere to the host tissues, increasing its contact surface, leading to a higher propagation and developing of virulence factors (Giolo and Svidzinski 2010). Under stress, C. albicans change from yeast form to hyphae, that it is closely interconnected with its pathogenicity, given that filamentous fungi present better adherence to the tissue since at the end of hyphae, there are enzymes that, when secreted, can degrade proteins, lipids
Fig. 5 Morphological transition of $C$. albincans in presence of subinhibitory concentrations of Piper caldense C.D.C. essential oil; Micrography was performed through 40X objective optical microscopy; photographic image captured in digital camera with $4 \mathrm{X}$ zoom and resized for better computer resolution. Growth control (A); P.caldense essential oil at $128 \mu \mathrm{g} / \mathrm{mL}(\mathbf{B})$; $256 \mu \mathrm{g} / \mathrm{mL}$ (C) and $512 \mu \mathrm{g} / \mathrm{mL}$

\section{Growth control}

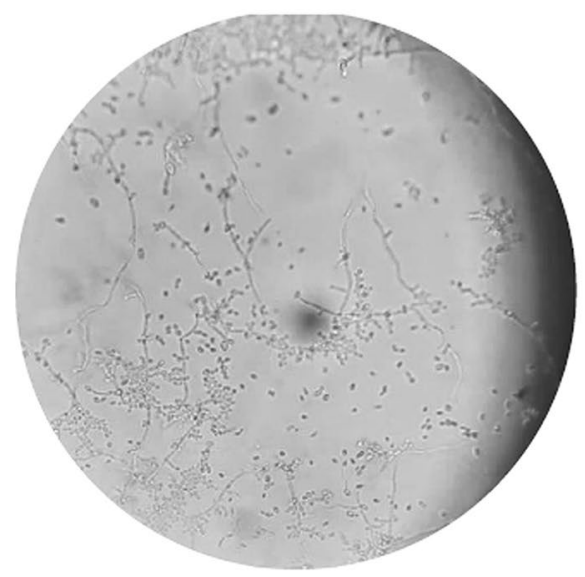

$256 \mathrm{ug} / \mathrm{mL}$

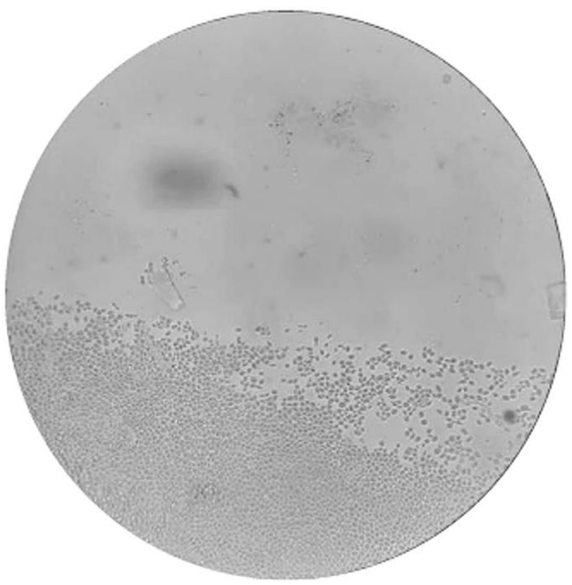

$128 \mu \mathrm{g} / \mathrm{mL}$

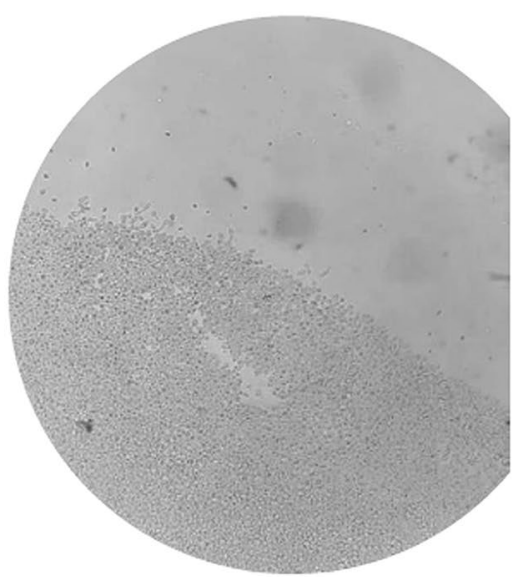

$512 \mathrm{ug} / \mathrm{mL}$

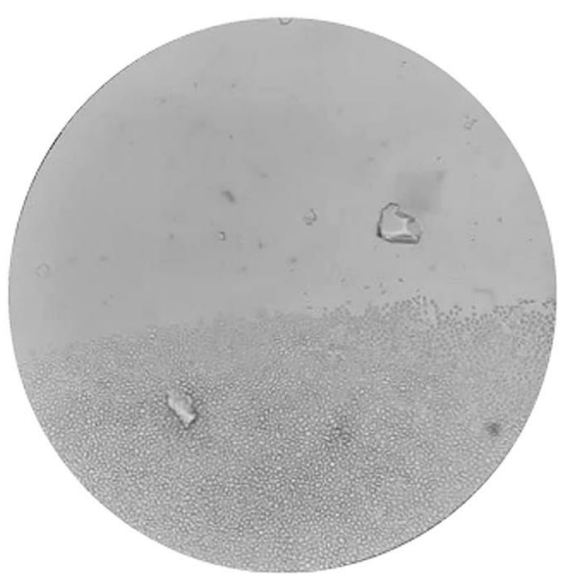


and other components of host cells, facilitating the invasion process (Costa et al. 2011).

The emission of hyphae is considerably relevant in what concerns the mechanism of candidiasis virulence since the pathogenicity of the fungus is due to the fact that it presents dimorphism, this appears as an aptitude method in the development of superficial and systemic infections that hyphae spread, promoting the pathogenicity of the infectious form (Morais-Braga et al. 2016).

Although there are several antifungals available on the market, the high frequency of resistant strains becomes worrying and borderline in several clinical conditions. Thus, the EOPC tested in the present study could be applied as an agent able to inhibit the conversion of commensal yeast cells of $C$. albicans in filamentous and pathogenic forms, in the treatment or prevention of candidiasis. It is important to note that cell differentiation is regulated by intracellular signaling pathways, including cAMP-PKA and MAPK pathways (Han et al. 2011). Regarding the inhibition of the filamentous form of fungi, it is suggested that inhibition of the Efg1 transcription factor associated with the PKA pathway, which stimulates the transcription of genes that participate in the formation of hyphae (Stoldt et al. 1997; Nobile et al. 2006).

\section{Conclusion}

EOPC showed antifungal action and it was able to inhibit the hyphae projection by $C$. albicans ATCC 10231, indicating a promise use in the treatment of candidiasis. In addition, the essential oil potentiating the activity of Norfloxacin decreasing its MIC values for resistant strains overexpressing NorA or MepA efflux pumps. Futhermore, EOPC promoted a significant reduction of the MIC values for $\mathrm{EtBr}$ indicating that the modulating effect could be related to its ability to cause inhibition of this efflux pumps. These results point to a potential of the EOPC as an adjuvant of Norfloxacin in the treatment of infections caused by $S$. aureus strains overproducing NorA or MepA efflux pumps, a protein overexpressed in S. aureus SA1199B. Besides NorA and MepA, EOPC was also to act as a QacC efflux pump inhibitor compound indicating a potential technological application in association with quaternary ammonia compounds for elimination of QacC overproducing S. aureus strains in both human and veterinary clinical environments.

Acknowledgements This study was supported by the Coordination for the Improvement of Higher Education Personnel-Brazil (CAPES), by the National Council for Scientific and Technological Development-Brazil (CNPq), by the Cearense Foundation for Scientific and Technological Development Support-Brazil (FUNCAP) and by the Piauí Research Foundation (FAPEPI).
Funding This work was supported by the National Council for Scientific and Technological Development-Brazil (CNPq) under Grant (no. 305719/2018-1) and by the Piauí Research Foundation (FAPEPI) under Grant (no. 050/2019).

Availability of data and materials All materials and data are stored at Department of Biological Chemistry, Regional University of Cariri, Ceará. Brazil, and may be shared upon request directed to the corresponding author.

\section{Declarations}

Conflict of interest The authors declare no conflict of interest.

Consent for publication No individual data are presented in this manuscript.

\section{References}

Ahmad A, Khan A, Manzoor N (2013) Reversal of efflux mediated antifungal resistance underlies synergistic activity of two monoterpenes with fluconazole. Eur J Pharm Sci 48:80-86

Balouiri M, Sadiki M, Ibnsouda SK (2016) Methods for in vitro evaluating antimicrobial activity: a review. J Pharm Anal 6:71-79

Barbedo LS, Sgarbi DBG (2010) Candidíase. DST-J Brasileiro De Doenças Sex Transm 22:22-38

Bezerra JWAB, Rodrigues FC, Da Cruz RP et al (2020) Antibiotic Potential and Chemical Composition of the Essential Oil of Piper caldense C. DC. (Piperaceae). Appl Sci 10:631

Cardozo Júnior EL, Chaves MCO (2003) Caldensin, a new natural n-Methylaristolactam from Piper caldense. Pharm Biol 41:216-218

Castro IMN, Vasconcelos Junior AA, Cunha FA et al (2016) Activity comparison of imidazole and triazole antifungals aga-inst $\mathrm{Can}$ dida albicans. Revista Brasileira De Anál Clín 48:216-222

Costa CR, Souza LKHe, Ataídes FS et al (2011) Molecular analysis and dimorphism of azole-susceptible and resistant Candida albicans isolates. Rev Soc Bras Med Trop 44:740-744

Costa LM, de Macedo EV, Oliveira FAA et al (2016) Inhibition of the NorA efflux pump of Staphylococcus aureus by synthetic riparins. J Appl Microbiol 121:1312-1322

Costa AR, de Lima SJ, Lima KRR et al (2017) Rhaphiodon echinus (Nees \& Mart.) Schauer: chemical, toxicological activity and increased antibiotic activity of antifungal drug activity and antibacterial. Microb Pathog 107:280-286

Costantin MB, Sartorelli P, Limberger R et al (2001) Essential oils from Piper cernuum and Piper regnellii: antimicrobial activities and analysis by GC/MS and 13C-NMR. Planta Med 67:771-773

Coutinho HDM, Costa JGM, Siqueira-Júnior JP et al (2008) In vitro anti-staphylococcal activity of Hyptis martiusii Benth against methicillin-resistant Staphylococcus aureus: MRSA strains. Rev Bras Farmacog 18:670-675

Coutinho HDM, Costa JGM, Falcão-Silva VS et al (2010) Effect of Momordica charantia L. in the resistance to aminoglycosides in methicilin-resistant Staphylococcus aureus. Comp Immunol, Microbiol Infect Dis 33:467-471

Dib I, Fauconnier ML, Sindic M et al (2017) Chemical composition, vasorelaxant, antioxidant and antiplatelet effects of essential oil of Artemisia campestris L. from Oriental Morocco. BMC Comp Alt Med 17:1-15 
Du D, Wang-Kan X, Neuberger A et al (2018) Multidrug efflux pumps: structure, function and regulation. Nat Rev Microbiology 16:523-539

Duarte AE, de Menezes IR, Bezerra Morais Braga MF et al (2016) Antimicrobial activity and modulatory effect of essential oil from the leaf of Rhaphiodon echinus (Nees \& Mart) Schauer on some antimicrobial drugs. Molecules 21:743

Egue LAN, Bouatenin J-PKM, N'Guessan FK et al (2018) Virulence factors and determination of antifungal susceptibilities of Candida species isolated from palm wine and sorghum beer. Microb Pathog 124:5-10

Faillace MS, Leal ALAB, Alcântara FAO, Ferreira JHL, Siqueira-Júnior JP, Nogueira CES, Barreto HM, Peláez WJ (2021) Inhibition of the NorA efflux pump of $S$. aureus by (Z)-5-(4fluorobenzylidene)-imidazolinines. Bioorg Med Chem Lett $31: 127670$

Fernandes L, Ribeiro H, Oliveira A et al (2020) Portuguese honeys as antimicrobial agents against Candida species. J Trad Compl Med 11:130-136

Ghavam M, Manca ML, Manconi M et al (2020) Chemical composition and antimicrobial activity of essential oils obtained from leaves and flowers of Salvia hydrangea DC. ex Benth. Sci Rep 10:15647

Giolo MP, Svidzinski TIE (2010) Fisiopatogenia, epidemiologia e diagnóstico laboratorial da candidemia. J Bras Patol Med Lab 46:225-234

Guimaraes DO, Momesso LD, Pupo MT (2010) Antibiotics: therapeutic importance and perspectives for the discovery and development of new agents. Quim Nova 33:667-679

Guschin A, Ryzhikh P, Rumyantseva T et al (2015) Treatment efficacy, treatment failures and selection of macrolide resistance in patients with high load of Mycoplasma genitalium during treatment of male urethritis with josamycin. BMC Infect Dis 15:40

Han T-L, Cannon RD, Villas-Bôas SG (2011) The metabolic basis of Candida albicans morphogenesis and quorum sensing. Fungal Genet Biol 48:747-763

Hou L, Chen Y, Ma C et al (2011) Effects of environmental factors on dimorphic transition of the jelly mushroom Tremella fuciformis. Cryptogam, Mycol 32:421-428

Houghton PJ, Howes MJ, Lee CC, Steventon G (2007) Uses and abuses of in vitro tests in ethnopharmacology: visualizing an elephant. J Ethnopharmacol 110:391-400

Kaatz GW, Seo SM, Ruble CA (1993) Efflux-mediated fluoroquinolone resistance in Staphylococcus aureus. Antimicrob Agents Chemother 37:1086-1094

Kaatz GW, McAleese F, Seo SM (2005) Multidrug resistance in Staphylococcus aureus due to overexpression of a novel multidrug and toxin extrusion (MATE) transport protein. Antimicrob Agents Chemother 49:1857-1864

Kamp G, Todt D, Pfaender S, Steinmann E (2020) Persistence of coronaviruses on inanimate surfaces and their inactivation with biocidal agents. J Hosp Infect 104:246-251

Klein S, Hannesen J, Zanger P et al (2020) Entry of Panton-Valentine leukocidin-positive methicillin-resistant Staphylococcus aureus into the hospital: prevalence and population structure in Heidelberg, Germany 2015-2018. Sci Rep 10(13243):1-7

Leal ALAB, Bezerra CF, Rocha JE et al (2019a) Piper cernuum Vell.: Chemical profile and antimicrobial potential evaluation. Ind Crops Prod 140:111577

Leal ALAB, Machado AJT, Bezerra CF et al (2019b) Chemical identification and antimicrobial potential of essential oil of Piper rivinoides kunth (BETIS-WHITE). Food Chem Toxicol 131:10559

Lima LFA, Lira AC, Coutinho HDM et al (2012) Antimicrobial resistance in staphylococci isolated from canine pyoderma. Comun Sci 3:181-185

Littlejohn TG, DiBerardino D, Messerotti LJ, Spiers SJ, Skurray RA (1991) Structure and evolution of a family of genes encoding antiseptic and disinfectant resistance in Staphylococcus aureus. Gene 101:59-66

Markham PN, Westhaus E, Klyachko K et al (1999) Multiple novel inhibitors of the NorA multidrug transporter of Staphylococcus aureus. Antimicrob Agents Chemother 43:2404-2408

Matias EFF, Santos KA, Falcão-Silva VS et al (2013) Modulation of the norfloxacin resistance in Staphylococcus aureus by Cordia verbenaceae DC Modulação da resistência à norfloxacina em Staphylococcus aureus por Cordia verbenaceae DC. Indian J Med Res 137:178-182

Mayers DL, Sobel JD, Ouellette M et al (2009) Antimicrobial drug resistance c: clinical and epidemiological aspects. Springer, Dordrecht Heidelberg

Morais-Braga MFB, Carneiro JNP, Machado AJT et al (2016) Highperformance liquid chromatography-diodic array detector, fungistatic, and anti-morphogenical analysis of extracts from Psidium brownianum Mart. ex DC. against yeasts of the genus Candida. Int J Food Prop 19:1837-1851

Neyfakh AA, Borsch CM, Kaatz GW (1993) Fluoroquinolone resistance protein NorA of Staphylococcus aureus is a multidrug efflux transporter. Antimicrob Agents Chemother 37:128-129

Nobile CJ, Andes DR, Nett JE et al (2006) Critical role of Bcr1dependent adhesins in C. albicans biofilm formation in vitro and in vivo. PLoS Pathog 2:e63

Rezende-Júnior LM, Andrade LMS, Leal ALAB (2020) Chalcones isolated from Arrabidaea brachypoda flowers as inhibitors of NorA and MepA multidrug efflux pumps of Staphylococcus aureus. Antibiotics 9(351):1-12

Rocha DS, Silva JM, Navarro DMAF et al (2016) Potential antimicrobial and chemical composition of essential oils from Piper caldense Tissues. J Mex Chem Soc 60:148-151

Ruiz-Reyes E, Suarez M (2015) Lactonas sesquiterpénicas. Diversidad estructural y sus actividades biológicas. Rev CENIC Cienc Biol 46:9-24

Sánchez-Martínez C, Pérez-Martín J (2001) Dimorphism in fungal pathogens: Candida albicans and Ustilago maydis-similar inputs, different outputs. Curr Opin Microbiol 4:214-221

Santos ALd, Santos DO, Freitas CCd et al (2007) Staphylococcus aureus: visitando uma cepa de importância hospitalar. J Bras Patol Med Lab 43:413-423

Schmidt E, Bail S, Friedl SM et al (2010) Antimicrobial activities of single aroma compounds. Nat Prod Commun 5:1934578X1000500906

Schindler BD, Frempong-Manso E, DeMarco CE et al (2014) Analyses of Multidrug Efflux Pump-Like Proteins Encoded on the Staphylococcus aureus Chromosome. Antimicrob Agents Chemother 59:747-748

Sellam A, Whiteway M (2016) Recent advances on Candida albicans biology and virulence. F1000Research, p 2582

Sidrin JJC, Rocha MFG (2010) Micologia médica à luz de autores contemporâneos. Guanabara Koogan, Rio de Janeiro

Siebra ALA, Oliveira LR, Martins AOBPB et al (2018) Potentiation of antibiotic activity by Passiflora cincinnata Mast. front of strains Staphylococcus aureus and Escherichia coli. Saudi J Biol Sci 25:37-43

Silva JA, Oliveira FF, Guedes ES et al (2014) Atividade antioxidante de Piper arboreum, Piper dilatatum e Piper divaricatum. Rev Bras Pl Med 16:700-706

Silva AKF, Reis AC, Pinheiro EEA et al (2021a) Modulation of the drug resistance by Platonia insignis Mart. extract, ethyl acetate fraction and Morelloflavone/Volkensiflavone (Biflavonoids) in Staphylococcus aureus strains overexpressing efflux pump genes. Curr Drug Metab 22:114-122

Silva PT, Xavier JC, Freitas TS et al (2021b) Synthesis, spectroscopic characterization and antibacterial evaluation by chalcones derived 
of acetophenone isolated from Croton anisodontus Müll.Arg. J Mol Structure 1226:129403

Skaltsa HD, Demetzos C, Lazari D et al (2003) Essential oil analysis and antimicrobial activity of eight Stachys species from Greece. Phytochemistry 64:743-752

Souza EL, Oliveira CEV, Stamford TLM et al (2013) Influence of carvacrol and thymol on the physiological attributes, enterotoxin production and surface characteristics of Staphylococcus aureus strains isolated from foods. Brazilian J Microbiol 44:29-35

Stoldt VR, Sonneborn A, Leuker CE et al (1997) Efg1p, an essential regulator of morphogenesis of the human pathogen Candida albicans, is a member of a conserved class of bHLH proteins regulating morphogenetic processes in fungi. EMBO J 16:1982-1991

Sugden R, Kelly R, Davies S (2016) Combatting antimicrobial resistance globally. Nat Microbiol 1:16187

Thai KM, Ngo TD, Phan TV et al (2015) Virtual screening for novel Staphylococcus aureus NorA efflux pump inhibitors from natural products. Med Chem 11:135-155

Tulgar S, Alasehir EA, Selvi O (2018) The antimicrobial activity of ephedrine and admixture of ephedrine and propofol: an in vitro study. Rev Bras Anestesiol 68:69-74

Veríssimo C, Sabino R, Martins C et al (2016) Fungal infections in Portugal - The sleeping giant. Infecção Sepsis 2:1-9

Veses V, Gow NA (2014) Pseudohypha budding patterns of Candida albicans. Med Mycol 47:268-275
Viana MG, Lutterbach MTS, Silva DR et al (2019) Antimicrobial and antibiofilm activity of essential oil of Lippia gracilis Schauer on Clostridium bifermentans and fungal-containing biofilms. Austin Chem Eng 6:1066

Wasicky R (1963) Uma modificação do aparelho de Clevenger para extração de óleos essenciais. Rev Farm Bioquim 1:77-81

Wightman R, Bates S, Amornrrattanapan P et al (2004) In Candida albicans, the Nim1 kinases Gin4 and Hsl1 negatively regulate pseudohypha formation and Gin4 also controls septin organization. J Cell Biol 164:581-591

Wright GD, Sutherland AD (2007) New strategies for combating multidrug-resistant bacteria. Trends Mol Med 13:260-267

Xiang Y, Li F, Dong N et al (2020) Investigation of a salmonellosis outbreak caused by multidrug resistant Salmonella Typhimurium in China. Front Microbiol 11:1-12

Yang D, Michel L, Chaumont JP et al (1999) Use of caryophyllene oxide as an antifungal agent in an in vitro experimental model of onychomycosis. Mycopathologia 148:79-82

Publisher's Note Springer Nature remains neutral with regard to jurisdictional claims in published maps and institutional affiliations. 